\title{
A IgReja CATÓlica e os problemas de saúde DA AMERICA DO SUL - VISÃO HISTÓRICA
}

\author{
Pe. Júlio Munaro *
}

\begin{tabular}{l|l}
\cline { 2 - 2 } & $\mathrm{RBEn} / 04$ \\
\hline
\end{tabular}

MUNARo, Pe. J. - A Igreja Católica e os problemas de saúde da América do Sul. Rev. Bras. Enf.; DF, 29 : 59-65, 1976.

A Igreja católica esteve presente no Continente Sul-Americano desde os primórdios de sua colonizaçāo e de entāo para cá vem exercendo significativa influência na vida global da população desta área geográfica do mundo, participando ativamente de seus destinos. A cultura, a política, a economia, a assistência social e de saúde são-lhe profundamente devedoras, tanto que pareceria impossivel escrever a história de qualquer um desses segmentos da atividade humana no continente sem levar em conta a participaçāo da Igreja católica e sua influência teórica e prática.

A conquista e a colonização da América do Sul podem ser consideradas obras exclusivas da Espanha e Portugal, duas naçōes solidamente ancoradas ao catolicismo e intimamente associadas à Igreja em sua ação. Com suas descobertas territoriais e graças à sua filosofia de vida abriram para a Igreja do século XVI vasto campo de atividade missionária, engajando-se com ela nesta grandiosa obra civilizadora. Ao mesmo tempo, porém, souberam vincular a Igreja à sua políti- ca de conquista e colonização. As contingências históricas da época, aliás, não concebiam outra saída para qualquer uma das partes.

O aumento crescente das forças eclesiásticas que tomaram parte na obra evangelizadora dos novos territórios portugueses e espanhóis contribuiu para dar maior volume à ação missionária patrocinada por Portugal e Espanha, incidindo profundamente em toda a vida dos novos territórios ou colônias.

Os Papas, desde Alexandre VI, foram os orientadores e guias dessa obra missionária, incentivando a propagaçāo do Evangelho, estimulando a implantação da Igreja local, defendendo os direitos dos nativos, combatendo a opressão, incrementando sua promoção e aculturação segundo os moldes europeus e cristãos.

Na prática, porém, o papado, envolvido e absorvido pelos problemas religiosos e políticos da Europa, delegou aos reis de Portugal e Espanha a tarefa de levar avante a evangelização missionária do século XVI favorecendo-os com privilégios e faculdades especiais tanto sobre os missionários quanto sobre as comu-

* Assistente do I Congresso Sul-Americano do CICIAMS. 
MUnaro, Pe. J. - A Igreja Católica e os problemas de saúde da América do Sul. Rev.

Bras. Enf.; DF, 29 : 59-65, 1976.

nidades religiosas e dioceses ou, em poucas palavras, sobre a vida geral da Igreja nos territórios de além mar, como muito bem transparece nas famosas "leis de Indias".

A Igreja e o Estado eram em Portugal e Espanha, mais que em qualquer outra parte da Europa, uma coisa só, numa espécie de prolongação extemporânea do sistema medieval de entrelaçamento vital entre Igreja e Estado. Portugal e Espanha viviam toda a sua vida em regime de Igreja. Todas as grandes empresas em que se metiam, mesmo de ordem puramente material, eram marcadas por esta mentalidade, verdadeira filosofia de estado. Não resta dúvida que, se de uma parte, os reis tinham sempre presente o bem da Igreja, de outra procuravam também seus interesses politicos, va'endo-se para tanto dos privilégios e faculdades especiais concedidos pelos Papas no tocante à direção de assuntos eclesiásticos, como os dízimos das Igrejas, os direitos patronais, o direito de apresentação dos prelados e outras dignidades eclesiásticas, de benefícios, mosteiros e lugares pios dos territórios de além mar. Era o "Direito de Patronato", que pertencia diretamente aos reis que, por sua vez, o delegaram ao Conselho de Indias, espécie de ministério encarregado de todos os assuntos das colônias tanto políticos, quanto econômicos e religiosos. O Conselho de Indias, por sua vez, delegou grande parte do poder às chamadas Audiências, estabelecidas nas próprias colonias e que aplicavam "in loco" as determinaçōes do Conselho.

o Direito de Patronato impunha a Portugal e Espanha o dever de zelar e fazer tudo quanto estivesse ao seu alcance para evangelizar os índios e implantar a Igreja. Competia-lhes transportar os missionários, distribuí-los no território, sustentá-los de proporcionar-lhes todos os recursos necessários para o bom desempenho da obra missionária. Não se tratava, evidentemente, de dar jurisdição eclesiástica aos reis sobre as missōes. Tratava-se de simples encargos de selecionar bons missionários, dar-lhes todo o apoio e respaldar sua ação evangelizadora e humanitária.

Os reis de Portugal e Espanha cumpriram fielmente a incumbência recebida como o atestam as leis, decretos e instruçōes para o Novo Mundo, em cujo teor a preocupação missionária transparece de forma evidente. "Promoveram sem descanso a conversão e a instrução dos indios, estabeleceram a hierarquia eclesiástica, criaram paróquias, erigiram mosteiros e casas religiosas e dispensaram contínua proteção aos missionários",

E verdade que os conquistadores, muitas vezes, buscavam com ânsia excessiva o ouro e as especiarias, maculando com seus negócios a obra missionária e ultrajando os direitos dos nativos. Tratava-se em grande parte de fenômenos limitados diante dos quais não faltaram reaçōes imediatas dos responsáveis.

A Igreja e o Estado, em suma, agiam intimamente unidos, em comunhão de interesses. Tudo era feito em comum e cm rigorosa interdependência, como na Idade Média. Havia unidade de ação.

As escolas, os hospitais, as farmácias, os teatros, o comércio, os políticos e os profissionais, enfim, estavam enquadrados neste conjunto sem dicotomias institucionais, que permitiu a conquista e a organização do Continente Sul-Americano, com instituiçōes em tudo semelhantes as que existiam em Portugal e Espanha e com funcionamento prático pouco ou nada inferior ao da metrópole, como era o caso das escolas, universidades e hospitais. Esta forma de ação durou praticamente três séculos.

Com o advento do movimento independentista que se alastrou por todo o continente em fins do século XVIII e que graças à participação da Igreja local alcançou o seu intento, a Igreja, e o Esta- 
MUNaro, Pe. J. - A Igreja Católica e os problemas de saúde da América do Sul. Rev. Bras. Enf.; DF, 29 : 59-65, 1976.

do foram-se dissociando até chegar à separaçāo completa - hostil ou amistosa - ou a uma forma de convivência um tanto artificial através de concordatos com a Santa Sé. A partir de entāo, as duas maiores forças do Continente sulamericano - Igreja e Estado foram tomando iniciativas próprias, às vezes no mesmo campo, como aconteceu no caso da educação e da saúde para citarmos dois exemplos apenas. A Igreja e o Estado superavam a situação medieval com todas as vantagens e deficiências que isto comportava

A Igreja ficou sem a proteção e os recursos materiais que lhe provinham do Estado e este, por sua vez, como detentor absoluto do poder civil, assumiu a responsabilidade pública pela assistência à coletividade. A Igreja, porém, fiel à sua missāo de serviço de fé e amor evangélicos, não se deteve ante as novas contingências históricas. Adaptou-se à nova realidade e prosseguiu em sua obra religiosa e humanitária em benefício de todos. Organizou no Continente vasta rede de hospitais, leprosários, ambulatórios, dispensários, escolas de enfermagem e até faculdades de medicina. Se, ainda hoje, suas instituições de saúde cerrassem abruptamente as portas, causariam transtornos imprevisíveis para a populacão e criariam gravíssimos problemas para os governos. Isto demonstra que a Igreja, mesmo após a separação com os Estados que surgiram, continuou encarnada na realidade do continente, participando da vida de todos, comungando suas qualidades e defeitos.

\section{PROBLEMAS GERAIS DE SAÚDE NA AMÉRICA DO SUL}

Os principais problemas de saúde da regiāo sul-americana provêm do subdesenvolvimento, que não é apenas cultural, científico, técnico e econômico, mas global. Por falta de instrução, de estruturas adequadas e de recursos técnicos suficientes grande parte de nossa população vive em condições de saúde pouco ou rada diferentes das que existiam há mais de um século. A alimentaçāo deficiente e inadequada, a habitaçāo precária, a carência de água tratada e de esgotos, moléstias endêmicas disseminadas por toda a parte, hospitais e leitos hospitalares insuficientes e mal distribuídos, profissionais de saúde concentrados nos grandes centros urbanos, politicas de saúde incertas e sem prioridades bem definidas, fazem do Continente SulAmericano uma área em condiçōes de saúde precárias, com taxas de mortalidade infantil elevadíssimas e com uma previsão média de vida muito abaixo dos países desenvolvidos.

Por falta de instrução as massas ignoram o que podem fazer para melhorar sua saúde, embora se observe por toda a parte um forte despertar de aspiraçōes, nem sempre corretamente avaliadas e, na maioria dos casos, sem discernimento do que compete à responsabilidade do indivíduo, da comunidade local e das autoridades públicas em seus vários níveis. Cria-se, desta forma, uma ansiosa expectativa no povo aliás muito justa, sem despertá-lo para a ação concreta a seu alcance, e de per si, suficiente para resolver pelo menos $50 \%$ dos problemas básicos de saúde que, de fato, são os que mais dizimam a nossa população.

A natureza de certos serviços essenciais nada tem de médico e muito menos devem ser esperados das autoridades constituídas. Os indivíduos e os pequenos grupos podem e devem assumir a iniciativa em benefício próprio. Nesta carência de iniciativa, talvez resida o mais grave problema de saúde do continente.

Urge argúcia política e habilidade administrativa para estabelecer e mensurar as necessidades prioritárias de saúde e utilizar ao máximo os recursos humanos e financeiros disponíveis. A empreitada não compete apenas a alguns 
MUNARo, Pe. J. - A Igreja Católica e os problemas de saúde da América do Sul. Ret. Bras. Enf.; DF, $29: 59-65,1976$.

mas a todos, pois todos dispomos de recursos humanos e financeiros e cada um deve ser o primeiro interessado em preservar, promover e tratar de sua saúde. Trata-se de educaçāo elementar, cuja responsabilidade recai, em primeiro lugar sobre as pessoas de melhor preparação cultural e profissional e mais diretamente ligados à conscientização do povo, como professores, jornalistas, políticos, médicos, enfermeiros, clero e autoridades. Não basta, todavia, conscientizar o povo de seus direitos e das situacoóes concretas que os contrariam. E preciso apontar caminhos, quem deve percorrê-los, como e com que recursos e onde encontrá-los. Já cedemos demais à tentação de imputar todos os nossos males às autoridades constituídas e ao invés de solucioná-los acabamos por agravá-los, distanciando sempre mais a solução. Precisamos encetar outro caminho, isto é, o de nossa responsabilidade e o de nossa colaboração. Talvez consigamos pouco, mas será o essencial. Parece que esquecemos que problemas graves muitas vezes têm soluçōes simples.

A Venezuela, desde 1966, desenvolveu um programa de medicina simplificada, com vistas à orientaçāo das atividades dos dispensários rurais no sentido de oferecer, na ausência de médicos, um mínimo de serviços preventivos e curativos bem definidos. Tais atividades são desenvolvidas por pessoas simples, com treinamento de alguns meses, que as habilita a prestar os primeiros socorros em caso de doenças, proporcionar educaçāo sanitária, vacinar e promover cuidados materno-infantis. Os resultados obtidos são animadores.

Os médicos descalços da China para citar um exemplo alienígena - com formação muito inferior aos médicos que superlotam os hospitais dos centros urbanos da América do Sul, têm condições de diagnosticar e curar com pouco mais de 100 tipos de medicamentos, $90 \%$ dos males daquele país, prestando um serviço inestimável à população rural e aos habitantes menos favorecidos dos grandes centros urbanos.

Talvez tenhamos que repensar toda a nossa mentalidade de cuidados de saúde, essencialmente voltada para o hospital, com instalaçōes e equipamentos caríssimos, com profissionais altamente especializados, mas que de fato atendem uma porcentagem mínima da população e, por sinal, a menos carente. Gastamos somas vultosas para corrigir males de saúde que, pelo menos em parte, poderiam ser prevenidos com recursos humanos e financeiros infinitamente inferiores aos que gastamos na terapia.

$\mathrm{Na}$ Colombia morrem mais de 250 crianças por dia, sendo que mais de 100 por desnutrição e suas consequências. Em certas regiōes do nosso Continente de 50 a $80 \%$ das crianças que freqüentam jardins de infância e escolas maternais são subnutridas. Falta alimento, é verdade. Há injustiças sociais que geram situaçōes lamentáveis e dramáticas para a saúde da papulação, mas existe sobretudo ignorância, fonte de quase todos os nossos males e entrave para qualquer solução.

A citação de exemplos como estes poderia ser multiplicada, partindo da realidade de quase todas as naçōes do nosso continente. Dispensamo-nos da tarefa, pois ela é muito fácil e ao alcance de todos. Revelam, porém, a precariedade geral de nossas condiçōes de saúde, e a necessidade de ação inteligente e coesa, inspirada no dever comum de promover e salvaguardar a saúde de todos, se quisermos superar a situação pouco animadora em que nos encontramos.

A instabilidade política tradicional do continente, o subdesenvolvimento econômico quase geral, a excessiva dependência das naçōes desenvolvidas e os hábitos inveterados do elitismo nos serviços gerais são fatores que merecem 
MUNARo, Pe. J. - A Igreja Católica e os problemas de saúde da América do Sul. Rev. Bras. Enf.; DF, 29 : 59-65, 1976.

nossa atenção se quisermos compreender a real situação de saúde da nossa população e como enfrentá-la.

A evoluçāo científica, técnica e social fez passos de gigante nas últimas décadas e prossegue em sua marcha vertiginosa sem dar mostras de cansaço. E pena que não se tenha generalizado nem qualitativa nem quantitativamente para benefício comum. Os povos que incorporam vitalmente o progresso são conhecidos pelo qualificativo de desenvolvidos, os demais ficam com o de subdesenvolvidos e entre ambos a qualidade de vida diferencia-se grandemente. Os subdesenvolvidos têm visão clara da meta a atingir, isto é o padrāo de vida de seus irmāos desenvolvidos, e lutam desesperadamente para alcancá-1o. Infelizmente nem sempre acertam o caminho. Empolgam-se com sucessos setoriais, nos quais apostam quase tudo o que têm, sem dar-se conta das renúncias básicas que isto comporta e dos sacrifícios coletivos que acarretam, cujo preço último são milhōes de vidas ceifadas prematuramente ou vividas em condiçōes muito inferiores ao mínimo desejável e possível. O continente Sul-americano, tomado como um todo, encontrase nesta situação. Luta pelo progresso, mas está envolto num caos de aspiraçōes. Concentra seus esforços nalguns pontos que reputa essenciais, mas que na realidade beneficiam uns poucos privilegiados ou atendem ao ufanismo curto de um país, e sacrificam a coletividade como um todo, retardando o progresso coletivo. A saúde não faz exceção.

\section{A IGREJA CATÓLICA FACE A ESTA REALIDADE}

Qual a sua posição? Sem dúvida, seu grande objetivo é de estar com o povo e servi-lo, participando de suas limitaçōes e de seus esforços, mantendo-se solidária com os mais desprovidos e fazendo o possível para amenizar-lhes o rigor da sorte.
Mas também ela é humana e sujeita na ação prática a todas as contingências da realidade-ambiente. Mantém a visão clara do ideal a atingir e o propõe com insistência. $\mathrm{Na}$ execução, porém, padece dos males comuns da nossa coletividade continental. Falta-lhe o senso das prioridades comezinhas, mas essenciais.

Suas obras de assistência à saúde merecem o respeito de todos e estāo disseminadas por toda a parte, prestando inestimáveis benefícios ao povo. Observamos, todavia, que também suas obras se ressentem de falta de coordenação e de prioridades bem ordenadas, diminuindo assim o seu resultado final possível. Não podemos negar a sua dedicação e trabalho abnegado. Esforçam-se sobremaneira para aperfeiçoar-se, buscam ampliar o seu atendimento, vão ao encalço de novos métodos, alargam-se geograficamente com real empenho. Nem sempre, porém, entendem toda a realidade e as soluçōes que comporta. Não se apercebem que um dos motivos por que o cuidado de saúde está ao alcance de poucos é a má distribuição dos recursos humanos e materiais e neste ponto nāo se distanciam do comportamento geral do continente. As novas descobertas científicas e técnicas obrigam-nas a novos investimentos em serviços e em pessoas para atender ao mesmo número limitado de pessoas, numa defasagem crescente face à dinâmica populacional e sua demanda de assistência.

Seus métodos têm-se demonstrado ineficazes no atendimento das necessidades globais de saúde da população. İevantamentos comunitários revelam que alcança apenas uma fração mínima da população em seus hospitais e não se poderia pretender mais, dadas as exigências modernas de tal tipo de atendimento. Mas seria este o serviço principal e mais urgente? Bastaria montar um serviço e aguardar que venham procurá-lo? Não estaria fazendo falta a iniciativa de ir ao encontro das reais ne- 
MUNARo, Pe. J. - A Igreja Católica e os problemas de saúde da América do Sul. Rev. Bras. Enf.; DF, 29 : 59-65, 1976.

cessidades da comunidade? O simples fato de observarmos ao redor de nossos hospitais católicos condiçōes de saúde intoleráveis impõe-nos o dever de um reexame de nossa atividade. Quando não havia à nossa disposição meios suficientes para melhorar as condiçōes gerais de saúde, podiamos justificar a dedicação exclusiva à medicina curativa. Hoje devemos adotar novas prioridades, baseadas na análise cuidadosa de medidas mais eficazes para a melhoria global da saúde. Não negamos que os serviços de saúde católicos não prestem assistência preventiva. Perguntamos apenas se de fato estāo fazendo o que podem e o que a população mais precisa neste campo. Dadas as finalidades específicas das instituiçōes eclesiais, estritamente voltadas para a promoção do povo, sem fins lucrativos, deveriam dar absoluta primazia à medicina preventiva, sobretudo quando compararmos os custos e os resultados desta com a curativa. Nossa desculpa geralmente baseia-se no fato de que nossas forças já são insuficientes para o atendimento dos casos médicos mais urgentes e isto desvia nossa atenção das atividades básicas como, cuidar do atendimento de milhares de crianças que precisam de melhor nutrição, de gestantes e mães carentes de orientação elementar, de lares sem as menores condiçōes de higiene, da orientação do povo para que use convenientemente os parcos recursos de que dispōe para a sua saúde.

\section{PERSPECTIVAS}

Em 1971, a Santa Sé criou a COR UNUM, entidade que tem por fim coordenar os esforços do mundo católico relacionados com o desenvolvimento e a assistência. O organismo não visa ditar normas, mas apenas estabelecer linhas gerais de conduta para os setores da Igreja que atuam neste campo, inclusive na área da saúde.
O organismo da Santa Sé sugere que a Igreja se interesse por todos os problemas de saúde, adaptando-se às necessidades locais e atendendo, de preferência, às comunidades periféricas e marginalizadas. Pede que as entidades católicas definam claramente os objetivos de sua atividade na área da saúde, estabelecendo como prioridade o que afeta $80 \%$ da população dos países em vias de desenvolvimento: problemas de imunizaçāo, de de nutrição, proteção materno-infantil, diagnóstico e tratamento de doenças comuns. Solicita, outrossim, que os religiosos escalonem suas atividades na comunidade, segundo a ordem acima indicada, planejando-as em ambito regional e nacional a fim de evitar desperdício de recursos humanos e financeiros, levando em conta os planos do governo, último responsável pela saúde pública. Os hospitais deverāo abrir-se para uma verdadeira assistência à populaçāo, dando sempre preferência às camadas populares mais carentes. Os leigos deverão ser interessados e formados para que assumam seus serviços de saúde, em espírito de solidariedade cristā. Recomenda, emfim, que a Igreja e se'is organismos evitem, na assistência à saúde, toda e qualquer sofisticação, empenhando-se em ampliar os serviços básicos, integrandoos num plano de desenvolvimento integral do homem, abrangendo educação, alimentação, habitação, comunicaçāo, etc.

COR UNUM compromete-se a proceder à coleta de todas as informaçōes possiveis que envolvam problemas e serviços de saúde e distribuí-los às dioceses, congregaçōes religiosas e outras entidades católicas que atuam no campo da saúde para que, partindo das informaçōes elaborem corretamente as diretrizes de sua atividade, com o objetivo de atender de forma conveniente às comunidades mais necessitadas. 
MUNARO, Pe. J. - A Igreja Católica e os problemas de saúde da América do Sul. Rev. Bras. Ent.; DF, 29 : 59-65, 1976.

Pede que as dioceses e comunidades religiosas ao instalarem novos serviços de saúde levem em conta o que já existe, harmonizando as instituiçōes entre si para complementação mútua e melhor atendimento da comunidade. Os projetos de saúde deverão ser assumidos e executados pelas comunidades envolvidas.

De modo geral a Igreja constata que apesar de todos os esforços dispendidos na área da saúde pelas congregaçōes religiosas, igrejas locais e outras entidades a ela diretamente ligadas, a grande maioria dos homens vive em ambiente insalubre e é vítima de doenças elementares. O problema, em grande parte, é de ordem política e reclama a formação de uma nova consciência face ao problema. Não pretende substituir nenhum governo e muito menos fazer-lhe concorrência. Pretende apenas apoiar seus esforços e colaborar com suas iniciativas. Quer situar seus projetos de saúde no contexto de uma aproximação comunitária e de um desenvolvimento integral, levando em conta todos os fatores que de alguma forma contribuem para tal melhoria, voltando-se para as categorias de pessoas mais suscetiveis, como as crianças $e$ as mães que representam na América do Sul cerca de $60 \%$ da população e dar prioridade absoluta aos projetos de abastecimento de água e esgotos, de alimentação, habitação, etc. Tais projetos despertam a participação da comunidade que deveria ser mobilizada para a educação sanitária através de pessoas da própria comunidade.

Dada a dificuldade de estender os serviços sanitários a toda a população por escassez de recursos humanos e financeiros e pelas grandes extensões geográficas, COR UNUM recomenda que tais serviços sejam os mais simples possiviveis. A comunidade seja atendida plurisetotorialmente por meio de auxiliares de formação adequada, com métodos de ação simplificados e bem definidos.

E interessante que a comunidade participe ativamente dos serviços de saúde organizados pela Igreja e que uma educação social e sanitária bem planejadas contribua para mobilizar seus recursos a fim de libertar as pessoas da doença, da pobreza e da ignorância.

Para remediar a insuficiência quantitativa da assistência à saúde da Igreja é necessário voltar a atenção para o nível qualitativo. A instalação de uma rede funcional de serviços, a coordenação desses serviços com os do governo, a implantação de medidas preventivas e curativas e a formação de pessoal sanitário que se adapte à realidade de cada região são medidas que ajudam a aumentar a eficácia do trabalho. A experiência demonstra que nas áreas menos desenvolvidas os auxiliares bem formados são tão eficientes quanto os especialistas.

Trata-se, como se vê, de diretrizes portadoras de novos enfoques para a ação da Igreja no campo da saúde. Certamente sua atuação não será imediata, muito menos abolidora das atividades existentes. Forçará, isto sim, uma nova linha de ação, benéfica para todos e estimuladora de novas atividades para a Igreja, aumentando ainda mais suas históricas benemerências no campo da saúde da América do Sul. 